\title{
ADAPTABILITY TO REVERSE LOGISTICS \\ - AN EMPIRICAL STUDY IN EUROPEAN ELECTRONICS INDUSTRY
}

\author{
Hans-Christian PFOHL \\ Alexander BODE \\ Ha Thi Van NGUYEN \\ Darmstadt University of Technology, Germany
}

\begin{abstract}
Reverse Logistics was previously not an important driver of supply chain in European electronics industry to create differentiation and cost reduction, suggesting that it might not be managed strategically. However, because of transformed market with the enforcements of laws, the scarcity of resources, and the more powerful customers, many companies have adjusted their existing supply chain to adapt to reverse logistics, which resolves the issues related to reverse flows for complying with the law, satisfying customers, and recapturing value. Reverse logistics has today become a competitive necessity and has gained increased acceptance of profitable business strategy. This study uses structural equation modeling technique with Partial Least Squares to examine how firms adapt to reverse logistics and its influences on reverse logistics performance. Empirical results relying on responses from 102 firms in European electronics industry indicate that there has been increasing adaptability to reverse logistics through resource commitments, strategy formulation, liberalized returns policy, capabilities and performance of reverse logistics. Testing indirect effects of resource commitments on performance of reverse logistics through multiple mediator models suggests that formulating a proper strategy of reverse logistics is currently the most important adaptability influencing performance of reverse logistics.
\end{abstract}

Keywords: Reverse Logistics, Adaptability, Resource Commitment, Strategy Formulation

\section{INTRODUCTION}

The European Working Group gives out the definition of Reverse Logistics (RL) with the focus on process orientation of planning, implementing and controlling backward flows of raw materials, inprocess inventory, packaging and finished goods, from a manufacturing, distribution or use point to a point of recovery or point of proper disposal (Brito and Dekker, 2002). According to this definition, the products and materials can be sent back either to the original manufacturer or to other companies involving in reverse supply chain providing services and operations related to collecting and reprocessing the returned products. Reverse logistics, therefore, is developed with inter-organizational networks and in relationship with different partners in supply chain.

Many companies perceived RL as cost center instead of profit center, and company policies did not support these operations (Pan Theo, 2009). Today, more companies have increasingly altered their company policies with more strategic focus on reverse logistics (Janse et al., 2009). Reverse logistics has played an increasingly critical role in overall corporate business (Daugherty et al., 2002) and been examined strategically within broader supply chain strategy. For example, many original equipment manufacturers (OEMs) such as Miele (Miele, 2008), Phillips (Phillip, 2010) and Electrolux (Electrolux, 2010) have been pioneers in reverse supply chain management through their innovations such as developing their eco-design products, involvement in product recovery, offering professional take-back services, and increasing their collaboration with supply chain partners to manage reverse flows more effectively and efficiently. More OEMs and distributors in European electronics industry have also adopted less restrictive returns policy, and offered customers more flexible services of collecting products through their reverse logistics systems (Verweij et al., 2008). They have increased resource allocations for RL to improve their capabilities of product acquisition, transport and handling, and product recovery in some extent (Kocabasoglu et al. 2005). For instance, OEMs are now more proactive with on-site collection for returns from business customers and maintenanceintensive goods because it gives the possibility to manage synergies between forward and reverse distribution and brings added value through asset recovery (Beullens, 2005). By paying attention to 
resource allocations and formulating RL strategy, more firms in European electronics industry, especially for medium and large-sized firms, can enhance customer satisfaction, improve company image, and increase their business profitability (Guide et al., 2008; Herold, 2007). For example, IBM Europe deals with returns originating mostly from expiring leases with business market. Other returns in IBM such as "old for new", buy-back initiatives, and commercial returns are operated by supply chain partners. IBM in Europe can resell around 80\% of the PCs returned from the business market and get the substantial benefits from their effective returns management (Fleischmann et al., 2004).

Although many studies in this field have been conceptual, focused on normative prescriptive analytical models, or based on limited case study analyses; the amount of research conducted to explore the adaptability to reverse logistics has been limited. Our research therefore focused on determining adaptability to RL under strategic considerations by exploring some dimensions including resource commitments, strategy formulation, liberalized returns policy, capability of returns handling and reprocessing, and performance of RL. Electronics industry is selected to explore research objectives because it is one of the key industries demonstrating the development of RL in Europe and this industry has more incentives to invest in reverse logistics than others do (Janse et al., 2009). The more powerful customers, the increasing multichannel retailers, and the growing enforcement of laws have direct impacts on the movement of goods throughout supply chain of European electronics industry, and particularly on the reverse flows (Verweij et al., 2008).

In the next section, theoretical background for the research is explored with some relevant terms and theories. A theoretical model and its key hypotheses are developed. Research methodology and empirical results of internet-based survey are then presented with some discussion of the findings. Finally, conclusions are presented along with research limitations and suggestions for future research.

\section{THEORETICAL BACKGROUND}

\section{Resource-based View (RBV)}

The term "resources" is broad in nature, in that it refers to not only physical (tangible) assets, such as equipments, plants, and location, but also to intangible assets, such as expertise, knowledge, and organizational assets (Zacharia et al., 2011). Resource-based theory views the firm as a bundle of idiosyncratic resources and assets, which emphasizes the use of rate, valuable, inimitable and unsubstitutable resources to gain sustainable competitive advantage (Barney, 1991). The resource-based view investigates the importance of internal resources in determining firm actions (Clemens and Douglas, 2006). The RBV is the most recent and fastest growing theoretical approach to explore strategy and green issues (Glen and Stuart, 2000). Reconfiguring resources for green logistics operations is nowadays critical for most firms (Zacharia et al., 2011), especially for RL because of its wide stages of processes, the complexity and uncertainty of different reverse flows, and the intensiveness of resource for RL implementation (Daughterty et al., 2001). Resource commitments and allocations to RL may be given more priority because of its influences on formulating strategy of RL, adjusting returns policy, and improving capabilities and performance of RL.

\section{Strategy Formulation}

Strategic management is the set of decisions and actions that result in the formulation and implementation of plans designed to achieve a company's objective (Pearce and Robinson, 2011). Strategy formulation is an ongoing process to develop and revise future-oriented strategies to allow an organization to achieve its objectives, considering its capabilities, constraints and the environment in which it operates (Harrison, 1999; Porter, 1985). In strategy formulation, it is necessary to modify current objectives and policies to adapt firms to the fast changing environments to perform more effectively (Andrews, 1980). A well-formulated strategy helps firms to bundle internal and external resources to address rapidly changing environments and achieve the effectiveness and efficiency of business performance (Quinn, 1981). To date, dealing with reverse flows has required the integrated management with different level, and more strategic focus on identifying the roles of returns, strategy of returns management, and specific policies for different types of returns (Janse et al., 2009).

By exploring the development of RL under strategic considerations, strategy formulation of a RL program is extracted from strategic returns management process suggested by Croxton et al., 2001 . Based on strategic returns management process, main activities for formulating strategy of RL are identified including developing goals and product recovery strategy for different kinds of return products, developing gate-keeping and disposition policies, developing RL networks and 
transportation options, developing returns policy and credit rules, and determining appropriate metrics for RL performance. This study investigates the processes of strategy formulation as developing a formal reverse logistics program (FRLP) (Autry, 2005; Croxton et al., 2001; Genchev, 2009; Richey et al., 2005). It is defined as strategic returns management process in which RL is regarded as important component of corporate strategy, gained resource commitments, specifically formulated with strategy, carefully developed with written policies and procedures, and clearly assigned with RL operations.

\section{Adaptability}

In recent years, increasing environmental dynamism and the adaptability of the firm have attracted new academic interests in how firms adapt to changes and obtain their effectiveness (Tuominen et al., 2004). Adaptability is known as a key prerequisite for good business performance, however, there is inconsistency in describing or defining the construct of adaptability (Andresen and Gronau, 2005). Wiendahl (1999) states that a factory is adaptable if it is possible to accomplish reactively or preactively the changes of the transformation objects (personnel, organization, and technology). Adaptability is also defined as the ease with which a system or parts of the system may be adapted to the changing requirements (EC96, 1996). Verweij et al. (2008) mention to 3As to realize an agile and efficient reverse chain within the Consumer Electronics industry including agility (the ability to respond to market changes), adaptability (the ability to adjust strategy, products and technologies), and alignment (the ability to align your organization, processes and systems).

Strategic analyses relies on industrial organization economics perspectives focusing on competitive forces and external fit (i.e. looking at the external business environment) to understand performance differences (Ainuddin et al., 2007). However, many scholars argue for the need to look inside organizations - at the resources within firms - for superior performance drivers and adaptability to fast changing environments (Rouse and Daellenbach, 1999). Therefore, adaptive capability also emphasizes the degree to which a firm can use a variety of company resources and organizational capabilities to achieve a desired end (Sanchez and Mahoney, 1996). As reverse logistics programs are resource intensive in terms of implementation and maintenance (Daugherty et al., 2001), the appropriate commitments and allocations of resources indicate primarily the adaptability to reverse logistics. Given these arguments, adaptability is defined in this study as the capabilities that a firm allocates resources to formulate strategy, adjusts company policies, and develops capabilities of RL to respond to external changes and achieve the effectiveness and efficiency of RL performance.

\section{HYPOTHESIS DEVELOPMENT}

Resource commitments relate to the allocation of "tangible and intangible" entities available to firms that enable them to make business efficiently and effectively (Hund and Morgan, 1996). Resourcebased view suggests that efficient and effective resource allocations can be the most important strategy to achieve competitive advantage (Grant, 2001). It means that resources can be used to develop capabilities that result in superior performance. The resource-capability-performance relationship has been confirmed in some studies relating to RL (Daugherty et al., 2004; Richey et al., 2005). The previous studies also show that the improved capabilities produce the superior performance when firm resources are committed sufficiently to the program (Jack et al., 2010; Richey et al. 2005). Das and Teng (2000) suggest three main types of resources including financial resource, technological resource and managerial resource that may affect RL capabilities, and therefore enhance performance of RL. Therefore, the arguments lead to the following hypotheses:

\section{$\boldsymbol{H}_{I}$ : Resource commitments are positively associated with capabilities of reverse logistics \\ $\mathrm{H}_{2}$ : Capabilities of reverse logistics are positively associated with performance of reverse logistics}

Strategic issues often require large amounts of firm's resources because they need certain commitments and allocations of people, physical assets, and money to set up specific strategic plans (Pearce and Robinson, 2011). Resources enable firms to conceive and implement strategies, improving effectiveness (Barney, 1991). Strategies are also the ways in which firms relate to their environment (Porter, 1985). They are the building blocks of managerial decisions and actions that determine the long-run performance of an organization. According to modern institutional approach of organizational theory and resource-based value, firms nowadays formulate their strategy depending on both interaction with external environments (Zhou and $\mathrm{Li}, 2010$ ) and co-alignment with internal resources (Edelman et al., 2005). Many researchers in strategic management recognize the 
competitive value of resources and identify how they combine with and influence the strategies pursued by the firm (Brush and Chaganti, 1998; Chandler and Hanks, 1994). In other words, they argue that firm strategies in conjunction with the firm's resource base determine firm performance. The commitment of resources is considered as an important base for formulating specific strategy of RL because investments in RL are more complicated and riskier than in forward supply chain (Kocabasoglu et al., 2005). Lack of resources may make the implementation of environmentallyoriented reverse logistics operations more difficult (Sarkis et al., 2009), and result in firms' reluctance to involve in RL management. Therefore, it is proposed that:

\section{$\boldsymbol{H}_{3}$ : Resource commitments are positively associated with strategy formulation of reverse logistics}

The strategic management literature suggests that organizations which give high emphasis to strategic planning and formulating are able to clearly identify their competitive advantages based on their internal resources and their interaction with external resources to get best business performance (Ainuddin et al., 2007; Tuominen et al., 2004). Strategic formulation of reverse logistics program facilitates firms to deal with reverse logistics management more proactively. By developing a formal reverse logistics program, firms can identify the ways to implement RL operations depending on the availability of company resources, the internal constraints, and the accessibility to wider range of external resources. According to Gooley (1998), a well-managed RL program could result in significant savings in inventory carrying cost, transportation cost, and waste disposal cost, which can create a substantial value-added and positively affect bottom-line. Therefore, we explore the viewpoints with the hypothesis:

\section{$\boldsymbol{H}_{4}:$ Strategy formulation of reverse logistics is positively associated with performance of reverse logistics}

Among the activities of strategy formulation, identifying a suitable return policy plays an important role in obtaining the competitive advantage with the rival in the same market. Returns policy mentions the degree of difficulty involved in returning and exchanging products, which can be divided into liberalized and restrictive returns policies. The increasing resource commitments to returns management may lead to less restrictive returns policy because the availability of resources for dealing with the issues of reverse flow. Companies may increasingly invest in the process of return merchandise authorizations, gate-keeping, and credit refund to meet customer demands (Mollenkopf et al., 2007). Therefore, it may lead to the hypothesis:

\section{$\boldsymbol{H}_{5}:$ Resource commitments is positively associated with liberalized returns policy}

A liberalized returns policy appears to be easier and quicker to receive authorization and credit for returns (Richey et al., 2005). By implementing a liberalized returns policy, firms should communicate and offer customer with more flexible after-sales services (Saccani et al., 2007), and thus may lead to increasing capabilities of take-back, repair, and redistribution. Return rates are now rising in Europe rapidly due to new EU policies governing internet sales and increasing customer power from both end-customers and multichannel retailer chain (Guide et al., 2006). Many consumers have grown accustomed to being able to bring electronics goods back to the store for just any reasons (Lawton, 2008). Firms offering customers more opportunities to return products discover that they must improve their capabilities in the area of RL and to more proactively manage their returned products (Autry, 2005). Therefore, liberalized returns policies may have positive influence on reverse logistics capabilities.

\section{$\boldsymbol{H}_{6}:$ Liberalized returns policy is positively associated with capabilities of reverse logistics}

The previous research showed that the improved capabilities produce the superior performance or effectiveness when firm resources are committed sufficiently to the program (Autry, 2005; Ellinger, 2001; R. G. Richey, S. E. Genchev, et al., 2005). The previous studies also state that a fit between the corresponding internal resources and firm strategies leads to enhanced performance (Chandler \& Hanks, 1994; Edelman et al., 2005). Therefore, if resource commitment is expected to impact strategy formulation, and capabilities of reverse logistics, these dimensions are posited to impact RL performance, and then an indirect effect can be explored. Therefore, it is likely to propose that:

$\mathrm{H}_{7}$ : Strategic formulation and capabilities of reverse logistics mediate the effect of resource commitments on RL performance.

Figure 1 describes the relationship of hypothesized links in theoretical model. 


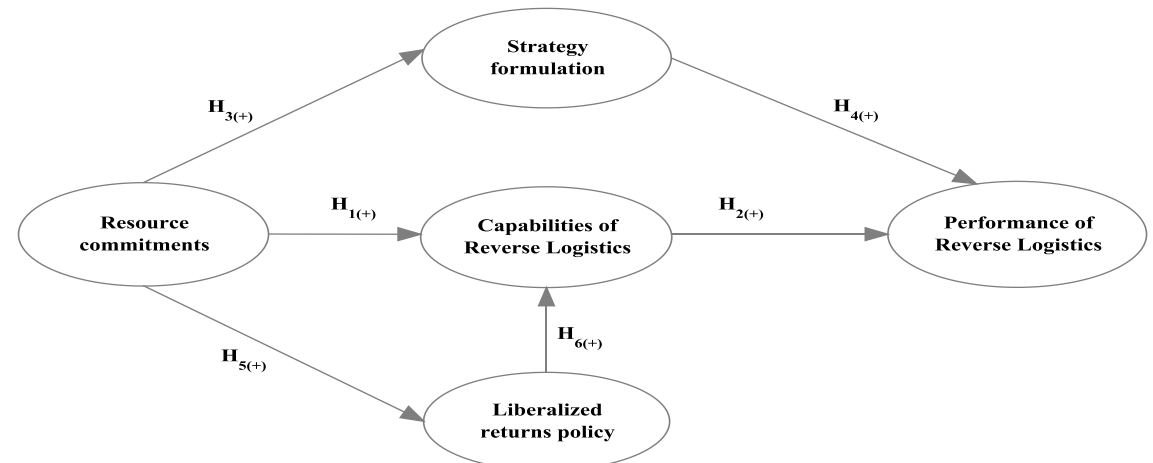

\section{EMPIRICAL RESULTS AND FINDINGS}

\section{Data collection}

Data were collected in European electronics industry to test the theoretical model via internet-based survey. Using the secondary resource from public domain of DIGITALEUROPE, the database of the study is established with a sample frame of 650 companies with the following characteristics: (1) manufacturers and distributors located in Europe, (2) of medium and large size according to EU criteria, and (3) belonging to electronics industry. A total of 102 valid responses is received and used in the analysis with a response rate of nearly $15.7 \%$. Among them, 65 firms are manufacturers and 37 firms are distributors. $68.6 \%$ of respondents are in related departments such as marketing and sales, customer service, logistics, reverse logistics and operation completing the questionnaire. Respondent companies dealing with manufacturing and distributing products in electronics industry are mostly located in Western Europe (66.7\%). Most respondent companies belong to medium and large size with the average annual turnover from 10 - 250 million EUR (66.7\%) and the number of employees more than $250(84.2 \%)$. Approximately $79.4 \%$ of respondent firms have implemented a reverse logistics program in their companies.

\section{Measurement scales and construct validity}

The proposed theoretical model is comprised of multi-item reflective constructs mostly derived from existing scales but some are developed for this study to evaluate the constructs of interests for research objectives. Consistent with Das and Teng (2000), a scale of resource commitments (RC) for implementing RL including managerial resource, financial resource, and technological resource is used with a five-point scale $(1=$ very much, $5=$ not at all $)$. The items used in this study to measure strategy formulation (SF) of reverse logistics are adapted from Croxton et al. (2001) with 5-point scale $(1=$ strongly agree, $5=$ strongly disagree). These new scale items are tested with exploratory factor analysis (EFA) and get the unidimensionality measurement. The respondent firms seem to be more strategic focus on reverse logistics with high mean score from 2.16 to 2.54 . The scale items for liberalized returns policy (LRP) are adapted from Richey et al. (2005) with two opposite statements and a five-point scale $(1=$ strongly agree, $5=$ strongly disagree). The average mean score of LRP (3.05) indicate that a less restrictive returns policy is today being carried out in European electronics industry.

Reverse logistics capabilities (TCAP) are developed with seven items. Some of items are adapted from the previous research of Autry (2005), Richey et al. (2005), and Shu (2007), while others are developed by suggestions from previous researchers and the popularity in today reverse logistics operations. A five-point scale $(1=$ very capable, $5=$ very incapable $)$ is used to measure RL capabilities. The EFA results for reverse logistics capabilities identify two distinct dimensions, which are labeled return handling capability (TCAP1) and reprocessing capability (TCAP2) with average mean score ranging from 1.98 to 3.21. Effectiveness and efficiency are components of performance management (Freires and Guedes, 2008). Scale measurement of RL performance is adapted from existing studies including improved customer satisfaction, improved competiveness (image and repute), cost reduction (transportation costs, waste disposal costs, material costs, redistribution costs) (Andel, 1997; Richey et al., 2005), improved profitability, and reduced inventory investment 
(Daugherty et al., 2001). RL performance is measured with a five-point scale ( $1=$ very effective, $5=$ very ineffective) and has mean score from 2.17 to 3.06.

We use Partial Least Squares (PLS) path modelling with variance-based technique by SmartPLS (Ringle, et al., 2005) to assess measurement model and the relationships between constructs (Fornell and Larcker, 1981). The analysis and interpretation of a PLS model consists of two-stage process. Firstly, the reliability and validity of the measurement model (outer model) is evaluated; then the assessment of structural model (inner model) is followed (Henseler et al., 2009). The reflective measurement model in PLS is evaluated in terms of reliability (individual item reliability, construct reliability), convergent validity, and discriminant validity (AVE, cross-loading). Table 1 presents the results of two measurement models based on capability of return handling (Model 1) and capability of reprocessing (Model 2).

The outer loadings of indicators in the measurement model of theoretical model mostly range from 0.533 to 0.939 , with most measures falling around or above 0.7 threshold value (Fornell and Larcker, 1981). Many studies have still retained measurements with loading below the 0.7 threshold due to their significance to theoretical model (Ainuddin et al., 2007; Hulland, 1999). Thus, the study eliminates only one indicator of strategy formulation construct (SF5) due to its lowest reliability (0.533), and dropping this indicator goes along with a substantial increase of composite reliability and average variance extracted of SF construct (Fornell and Larcker, 1981). The composite reliability values of all constructs studied in research model range from 0.84 to 0.92 , suggesting that high internal consistency reliability and being regarded as satisfactory (Nunnaly and Bernstein, 1994). All values of average variance extracted (AVE) are greater than the minimum value of 0.5 , meaning that latent variables in measurement model can explain more than half of the variance of its indicators on average. Therefore, the results support for the convergent validity of all constructs (Fornell and Larcker, 1981). Fornell and Larcker's (1981) test for discriminant validity indicates high square root AVE for each factor exceeding the inter-correlation of the construct with the other construct in the models. The tests suggest that the discriminant validity is supported (Chin, 1998; Fornell and Larcker, 1981). 
Table 1: Results of Measurement Model

\begin{tabular}{|c|c|c|c|c|}
\hline \multirow[b]{2}{*}{$\begin{array}{l}\text { Measurement items } \\
\quad(\text { Scale 1-5) }\end{array}$} & \multicolumn{2}{|c|}{ Model 1} & \multicolumn{2}{|c|}{ Model 2} \\
\hline & $\begin{array}{l}\text { Standardized } \\
\text { loading/AVE }\end{array}$ & $\begin{array}{l}\text { Composite } \\
\text { reliability }\end{array}$ & $\begin{array}{l}\text { Standardized } \\
\text { Loading/AVE }\end{array}$ & $\begin{array}{l}\text { Composite } \\
\text { reliability }\end{array}$ \\
\hline Resource commitments (RC) & $0.650^{a}$ & 0.842 & 0.650 & 0.842 \\
\hline RC1: Managerial resource commitment & 0.873 & & 0.877 & \\
\hline RC2 : Financial resource commitment & 0.902 & & 0.899 & \\
\hline RC3 : Technological resource commitment & 0.602 & & 0.600 & \\
\hline Strategic formulation (SF) & 0.619 & 0.867 & 0.619 & 0.867 \\
\hline SF1: Product recovery strategy & 0.781 & & 0.781 & \\
\hline SF2: Gate-keeping and disposition policies & 0.765 & & 0.765 & \\
\hline SF3: RL networks and transport options & 0.795 & & 0.795 & \\
\hline SF4: Returns policy and credit rules & 0.806 & & 0.806 & \\
\hline SF5: Metrics of RL performance (*) & $\underline{0.533}$ & & $\underline{0.533}$ & \\
\hline Returns policy (LRP) & 0.852 & 0.920 & 0.851 & 0.920 \\
\hline RP1: Restrictive returns policy $(r)$ & 0.933 & & 0.939 & \\
\hline RP2: Liberalized returns policy & 0.913 & & 0.906 & \\
\hline Return handling capability (TCAP1) & 0.741 & 0.896 & & \\
\hline CAP1: Collecting and Gate-keeping & 0.881 & & & \\
\hline CAP4: Ease of credit refund & 0.847 & & & \\
\hline CAP5: Remarketability & 0.854 & & & \\
\hline Reprocessing capability (TCAP2) & & & 0.636 & 0.839 \\
\hline CAP2: Product recovery & & & 0.850 & \\
\hline CAP3: Material recovery & & & 0.715 & \\
\hline CAP6: Quality of rework and repair & & & 0.821 & \\
\hline Reverse logistics performance (EFF) & 0.645 & 0.900 & 0.645 & 0.900 \\
\hline EFF1: Customer satisfaction & 0.846 & & 0.849 & \\
\hline EFF2: Corporate image & 0.862 & & 0.863 & \\
\hline EFF3: Cost reduction & 0.764 & & 0.734 & \\
\hline EFF4: Improved profitability & 0.780 & & 0.781 & \\
\hline EFF5: Reduced inventory investment & 0.775 & & 0.778 & \\
\hline
\end{tabular}

(*): Items were dropped from the study because of drop-off rules, $(r)$ : reverse recoding, $\left({ }^{a}\right)$ : AVE of each construct

\section{Structural model and Hypotheses testing}

For assessing the inner path model and examining the proposed hypotheses, the important criterion for explanatory power of a PLS model is the coefficient of determination $\left(R^{2}\right)$ of the dependent latent variables (Chin, 1998) and the effect size by means of Cohen's (1988) $f^{2}$ (Henseler et al., 2009). The 
bootstrap procedure with 1000 samples is used to calculate the significance of the path coefficients (Chin, 1998). As noted in Table $2, \mathrm{RC}$ has positive impacts on TCAP $\left(\beta_{1}=0.289, \mathrm{p}_{1}<0.01 ; \beta_{1}=0.399\right.$, $\left.\mathrm{p}_{1}<0.01\right)$. The hypothesis $\left(\mathrm{H}_{1}\right)$ is significantly supported, indicating that more resources are committed and allocated to increase capabilities of RL especially for capabilities of reprocessing. By using an incremental $\mathrm{F}$ test for effect size defined for $\mathrm{R}^{2}$, the study find small effect size of $\mathrm{RC}$ on the variance explained for TCAP1 $\left(\mathrm{f}_{1}^{2}=0.084\right)$, but the moderate effects on TCAP2 $\left(\mathrm{f}_{2}{ }_{2}=0.227\right)$.

As demonstrated in Table 2 , we also identify a significantly positive relationship between LRP and TCAP $\left(\beta_{1}=0.349, \mathrm{p}_{1}<0.01 ; \beta_{2}=0.344, \mathrm{p}_{2}<0.01\right)$, suggesting that the trend of less restrictive returns policy in Europe has forced firms to enhance their capabilities of reverse logistics. Therefore, liberalized returns policy has motivated the adaptability to reverse logistics in business and marketing perspective with the focus on customer orientation. $F$ test for effect size signifies moderate effect (i.e. $\mathrm{f}^{2}{ }_{1}=0.122, \mathrm{f}_{2}{ }_{2}=0.153$ ), suggesting that firms improve their services for repair/rework to satisfy customers, as well as increase their capabilities of collecting and gate-keeping, refunding credit to customers and redistributing.

The large effect is shown through the coefficient path between $\mathrm{RC}$ and $\mathrm{SF}\left(\beta_{1}=0.660, \mathrm{p}_{1}<0.01 ; \beta_{2}=\right.$ $0.661, \mathrm{p}_{2}<0.01$ ), suggesting that hypothesis $\mathrm{H}_{3}$ is highly supported. More resources committed lead to more strategic focus on returns issues and RL management, especially for managerial resources $(\beta=0.377, \mathrm{p}<0.01)$ and financial resources $(\beta=0.299, \mathrm{p}<0.01)$.

Table 2: Results of hypotheses testing

\begin{tabular}{|c|c|c|c|c|}
\hline \multirow[b]{2}{*}{ Structural relationships } & \multicolumn{2}{|c|}{ Model 1} & \multicolumn{2}{|c|}{ Model 2} \\
\hline & $\begin{array}{l}\text { Standardized } \\
\text { estimate }\end{array}$ & t-value & $\begin{array}{l}\text { Standardized } \\
\text { estimate }\end{array}$ & $\mathrm{t}$-value \\
\hline $\mathrm{RC} \rightarrow \mathrm{TCAP}\left(\mathrm{H}_{1}\right)$ & 0.289 & 3.298 & 0.424 & 5.154 \\
\hline TCAP -> EFF $\left(\mathrm{H}_{2}\right)$ & 0.234 & 3.652 & 0.318 & 3.802 \\
\hline $\mathrm{RC} \rightarrow \mathrm{SF}\left(\mathrm{H}_{3}\right)$ & 0.660 & 14.082 & 0.661 & 13.603 \\
\hline $\mathrm{SF} \rightarrow \operatorname{EFF}\left(\mathrm{H}_{4}\right)$ & 0.646 & 9.612 & 0.581 & 7.200 \\
\hline $\mathrm{RC} \rightarrow>\operatorname{LRP}\left(\mathrm{H}_{5}\right)$ & 0.559 & 9.021 & 0.561 & 9.672 \\
\hline $\mathrm{LRP} \rightarrow \mathrm{TCAP}\left(\mathrm{H}_{6}\right)$ & 0.349 & 3.932 & 0.344 & 3.892 \\
\hline \multirow{2}{*}{$\begin{array}{l}\text { Prediction-oriented } \\
\text { measurement }\end{array}$} & \multicolumn{2}{|c|}{$G o F_{1}=0.543$} & \multicolumn{2}{|c|}{$G o F_{2}=0.562$} \\
\hline & \multicolumn{2}{|c|}{$R^{2}=0.618$} & \multicolumn{2}{|c|}{$R^{2}=0.646$} \\
\hline
\end{tabular}

Interestingly, we find that RC have positive impacts on LRP, suggesting that hypothesis $\mathrm{H}_{5}$ is significantly supported $\left(\beta_{1}=0.559, \mathrm{p}_{1}<0.01 ; \beta_{2}=0.561, \mathrm{p}_{2}<0.01\right)$. The empirical results show that more $\mathrm{RC}$ helps respondent firms identify the strategic importance of customer returns, and the benefits of liberalized returns policies in improving company image, and increasing customer satisfaction and sales.

TCAP is positively related with EFF $\left(\beta_{1}=0.234, \mathrm{p}_{1}<0.01 ; \beta_{2}=0.318, \mathrm{p}_{2}<0.01\right)$, indicating that hypothesis $\mathrm{H}_{2}$ is supported. The results indicate that firms have been adaptive to RL by utilizing internal resources to increase their capabilities of RL. However, the moderate effect size of TCAP on EFF (i.e. $\mathrm{f}_{1}{ }_{1}=0.107, \mathrm{f}_{2}{ }_{2}=0.195$ ) indicates that respondent firms have not totally been proactive in RL operations. Meanwhile, $\mathrm{SF}$ is found to have substantial effect on EFF, suggesting that hypothesis $\mathrm{H}_{4}$ is highly supported. Specifically, the higher level of strategic formulation of RL program firms have, the more effective performance of reverse logistics firms can achieve $\left(\beta_{1}=0.646, p_{1}<0.01 ; \beta_{2}=0.581\right.$, $\left.\mathrm{p}_{2}<0.01\right)$. Developing a formal RL program gives rise to the large effect size on performance of RL.

The $R^{2}$ values for capabilities of $R L\left(R_{1}^{2}=0.318, R_{2}{ }_{2}=0.463\right)$ indicate that the adjustments of resources and returns policy have improved moderately the capabilities of RL, suggesting the more adaptability to reverse logistics. Especially, the effects of strategy formulation and capabilities of RL explain more than $60 \%$ of variance in performance of RL, demonstrating that they are important dimensions of adaptability to reverse logistics at respondent firms. The main effects of empirical 
results indicate the higher adaptability to RL at firm level. GoF values of 0.543 and 0.562 for model 1 and model 2, respectively, exceed the cut-off value of 0.36 for large effect size indicating that the theoretical model performs well compared to the baseline values and relatively fit in the data collected (Tenenhaus, 2005).

\section{Further analysis of mediation effects}

Multiple mediator models may provide a more accurate assessment of mediation effect of RC on performance of RL through strategy formulation and capabilities of RL. For assessing specific indirect effects in multiple mediator models, we use bootstrapping method suggested by Shrout and Bolger (2002) with PLS path model analysis of 1000 resamples to calculate the effect size, standard errors (SE), z-values, and confidence intervals of indirect effect. The results of bootstrapping indirect effects indicate that the effect of RC on RL performance is partially mediated by SF and TCAP. The indirect effect of RC on EFF through TCAP is statistically significant $\left(\beta_{\text {indirect }}^{1}=0.039, z=1.887, p<0.1\right.$; $\left.\beta^{2}{ }_{\text {indirect }}=0.071, \mathrm{z}=1.836, \mathrm{p}<0.1\right)$ and excludes zero in the confident interval, indicating that the effect of resource allocations and commitments through processing capabilities on performance of RL appear to be more effective and efficient. However, the effect size is rather small in comparison with the indirect effect of RC on EFF through SF $\left(\beta_{\text {indirect }}^{1}=0.267, z=4.082, p<0.01 ; \beta_{\text {indirect }}^{2}=0.262\right.$, $\mathrm{z}=3.940, \mathrm{p}<0.01$ ).

As observed in Table 3, RC relates significantly to LRP, in turn LRP relates significantly to TCAP, and finally TCAP significantly relates to performance of RL. This causal chain manifests dual mediation effect between RC, LRP, TCAP and EFF, likely indicating significant indirect effect of RC on EFF through LRP and TCAP. We also use bootstrapping method to test for dual mediation effect. Two single indirect effects in this causal chain are tested independently to examine the significance of dual mediation effect. The results in Table 3 show that both of them are statistically significant and excludes zero in the confidence interval. Moreover, the dual mediation effect is significantly positive $\left(\beta_{\text {indirect }}^{1}=0.027, \mathrm{z}=1.895, \mathrm{p}<0.1 ; \beta^{2}\right.$ indirect $\left.=0.032, \mathrm{z}=1.935, \mathrm{p}<0.1\right)$, indicating the adaptability to $\mathrm{RL}$ by committing and allocating internal resources have substantially influenced the performance of reverse logistics through both strategic and operational policies.

Table 3: Test results of indirect effects

\begin{tabular}{lcccccc}
\hline \multirow{2}{*}{ Indirect effects } & \multicolumn{3}{c}{ Model 1 } & & \multicolumn{2}{c}{ Model 2} \\
& Estimate & SE & $\begin{array}{c}95 \% \text { CI Bootstrap } \\
\text { Percentile }\end{array}$ & Estimate & SE & $95 \%$ CI Bootstrap \\
& & & & & Percentile \\
\hline RC-TCAP-EFF & $0.039(1.887)$ & 0.021 & {$[0.006-0.084]$} & $0.071(1.836)$ & 0.038 & {$[0.002-0.150]$} \\
RC-SF-EFF & $0.267(4.082)$ & 0.065 & {$[0.148-0.399]$} & $0.262(3.940)$ & 0.066 & {$[0.134-0.395]$} \\
RC-LRP-TCAP & $0.198(3.784)$ & 0.052 & {$[0.101-0.310]$} & $0.199(3.361)$ & 0.059 & {$[0.088-0.326]$} \\
LRP-TCAP-EFF & $0.050(1.939)$ & 0.026 & {$[0.008-0.109]$} & $0.058(2.016)$ & 0.028 & {$[0.003-0.117]$} \\
RC-LRP-TCAP-EFF & $0.027(1.895)$ & 0.014 & {$[0.005-0.061]$} & $0.032(1.935)$ & 0.016 & {$[0.002-0.070]$} \\
\hline
\end{tabular}

\section{CONCLUSIONS AND SUGGESTIONS}

The empirical results demonstrate adaptability to RL in European electronics firms in some extent. The partial mediation effect reveals that resource commitments have both significant direct and indirect effects on performance of RL. The wide stage processes of RL and the complexity of reverse flows require the intensiveness of resources for RL implementation. Therefore, the appropriate allocations of resource lead to more strategic focus on RL management, more attention in formalizing returns policy, more improved capabilities, and more effectiveness and efficiency of RL performance, suggesting the better adaptability to reverse logistics. The mediating role of capabilities of RL indirect effect on performance of RL suggest that firm should focus more on their internal capabilities to enhance the effectiveness and efficiency of RL operations. Greater indirect effect through strategy formulation may suggest that firms in European electronics industry now focus more on strategic formulation of a formal reverse logistics program by interacting the resources and capabilities from 
both internal and external environments to implement RL effectively. Commitments of resources, especially for management and finance have made firms more proactive in finding the best solutions for managing different reverse flows.

Formulating a proper strategy of RL may create the significant effects on performance of RL because it supports firms in identifying the strategic roles of RL, eliminating ambiguity, and clarifying priorities for RL in the process of integrated supply chain management, based on their internal resources and core activities. Therefore, managers can be aware of synergic effects of resources investment on forward and reverse supply chain, and make important decisions of in-house operations or outsourcing reverse logistics. For example, investments in new product development can incorporate with product eco-design for easily disassembly and recycling; investment in improving customer after-sales services can bring direct benefits to both forward and reverse supply chain management; or joining collective take-back scheme can reduce the costs of RL in EoL management. Increasing resource commitments and concerns in formulating a formal RL program properly has manifested more proactive adaptability to reverse logistics in today fast changing environments.

The study focuses on electronics industry in Europe; therefore, it may be limited to the generalized conclusions for other industries in adaptability to RL. However, electronics industry has greater motivations in implementing RL for both EoL management and customer returns management than other industries. Future research should diversify the industries to provide greater generalizability and extend current knowledge of adaptability to RL, e.g. garments and textiles industry or publishing industry. The research was also somewhat constrained by the sample size due to the time and financial constraints. However, the fit indices of measurement model were relatively accepted, suggesting the results are fundamentally significant and relevant. If the future research extends to other industries, it can support for greater generalization and secure larger sample size, thus in turn high value of significance. The study used only internet-based quantitative analysis. The survey method is very strongly useful and supports testing the research hypotheses. The future research should combine qualitative analysis with case studies to extract the practical insights of adaptability to reverse logistics. 


\section{REFERENCES}

Ainuddin, R., Beamish, P., Hulland, J. and Rouse, M. (2007). Resource attributes and firm performance in international joint ventures. Journal of World Business, 42(1), 47-60. doi:10.1016/j.jwb.2006.11.001

Andel, T. (1997). Reverse logistics: a second chance to profit whether, through refurbishment or recycling, companies are finding profits in returned products. Transportation and Distribution, 38(7), 61-64.

Andresen, K. and Gronau, N. (2005). An Approach to Increase Adaptability in ERP Systems An. Management Review, 15-18.

Andrews, K. R. (1980). The concept of Corporate Strategy (pp. 1-87). Homewood: Irwin.

Autry, C. W. (2005). Formalization of reverse logistics programs: A strategy for managing liberalized returns. Industrial Marketing Management, 34(7), 749-757. doi:10.1016/j.indmarman.2004.12.005

Autry, C. W., Daugherty, P. J. and Richey, G. (2001). The challenge of reverse logistics in catalog retailing. International Journal of Physical Distribution \& Logistics Management, 31(1), 26-37. doi:10.1108/09600030110366384

Barney, J. B. (1991). Firm resources and sustained competitive advantage. Journal of Management, 17(1), 99-120.

Beullens, P. (2005). Reverse logistics in effective recovery of products from waste materials. Reviews in Environmental Science and Bio/Technology, 3(4), 283-306. doi:10.1007/s11157-004-2332-3

Brito, M. P. D. and Dekker, R. (2002). A Framework for Reverse Logistics. Econometric Institute Report EI 2002-38SSRN eLibrary. Rotterdam.

Brush, C. G. and Chaganti, R. (1998). Business without glamour? An analysis of resources on performance by size and age in small service and retail firms. Journal of Business Venturing, 9026(97), 233-257.

Chandler, G. N. and Hanks, S. H. (1994). Market attractiveness, resourced-based, capabilities, venture strategies, and venture performance. Journal of Business Venturing, 9, 331-349.

Chin, W. W. (1998). The partial least squares approach to structural equation modeling. In G. A. Marcoulides (Ed.), Modern Methods for Business Research (pp. 295-358). Mahwah, NJ: Lawrence Erlbaum Associates.

Clemens, B. and Douglas, T. J. (2006). Does coercion drive firms to adopt voluntary green initiatives? Relationship among coercion, superior firm resources, and voluntary green initiatives. Journal of Business Research, 59, 483 - 491.

Croxton, K., Dastugue, S. G., Lambert, D. M. and Rogers, D. S. (2001). The Supply Chain Management Processes. The International Journal of Logistics Management, 12(2), 19.

Das, T. K. and Teng, B. S. (2000). A resource-based theory of strategic alliances. Journal of Management, 26(1), 31-61.

Daugherty, P. J., B.Myers, M. and Richey, R. G. (2002). Information support for reverse logistics: the influence of relationship commitments. Journal of Business Logistics, 23(1), 85-106.

Daugherty, P., Richey, R. G., E.Genchev, S. and Chen, H. (2004). Revese logistics: superior performance through focused resource commitments to information technology. Transportation Research Part E, 41, 77-92.

Daugherty, Patricia J., Chad W. Autry, and A. E. E. (2001). Reverse Logistics: The Relationship Between Resource Commitment and Program Performance. Journal of Business Logistics, 22, 107123.

Dowell Glen, Hart Stuart, Y. B. (2000). Do corporate environmental standards create or destroy market value? Management Science, 46(8), 1059-1074.

EC96. (1996). Adaptability in Object-Oriented Software Development. Workshop Report, 10th European Conference on Object-Oriented Programming Development (pp. 1-17). 
Edelman, L. F., Brush, C. G. and Manolova, T. (2005). Co-alignment in the resource - performance relationship: strategy as mediator. Journal of Business Venturing, 20, 359 - 383.

doi:10.1016/j.jbusvent.2004.01.004

Electrolux (2010). Electrolux Annual Report 2010.

Ellinger, A. E. (2001). Reverse logistics: The relationship between resource commitment and program performance. Journal of Business Logistics, 22(1), 107-123.

Fleischmann, M., Nunen, J. V., Gräve, B. and Gapp, R. (2004). Reverse Logistics - Capturing Value in the Extended Supply Chain. Management (pp. 1-23). Rotterdam. Retrieved from www.erim.eur.nl

Fornell, C. and Larcker, D. (1981). Evaluating Structural Equation Models with Unobservable Variables and Measurement Error. Journal of Marketing Research, 18(1), 39-50.

Freires, F. G. and S.Guedes, A. P. (2008). Power and Trust in Reverse Logistics System for Scraptires and its Impact on Performance. JOSCM, 1(1), 57-65.

Genchev, S. (2009). Reverse logistics program design: A company study. Business Horizons, 52(2), 139-148.

González-Torre, P., Alvarez, M., Sarkis, J. and Adenso-Díaz, B. (2009). Barriers to the implementation of environmentally oriented reverse logistics: Evidence from the automotive industry sector. British Journal of Management, 21(4), 889-904.

Gooley, T. B. (1998). Reverse logistics: five steps to success. Management and Distribution Report, 37(6), 49 - 55.

Grant, R. (2001). Resource-based theory of competitive advantage: Implications for Strategy Formulation.

Guide, V. D. R., Gunes, E. D., Souza, G. C., \& Wassenhove, L. N. (2008). The optimal disposition decision for product returns. Operations Management Research, 1(1), 6-14. doi:10.1007/s12063-0070001-8

Guide, V. D. R., Souza, G. C., Van Wassenhove, L. N., \& Blackburn, J. D. (2006). Time Value of Commercial Product Returns. Management Science, 52(8), 1200-1214. doi:10.1287/mnsc.1060.0522

Harrison, E. F. (1999). The Managerial Decision-Making Process (5th ed.). Boston: Houghton Mifflin.

Henseler, J., M.Ringle, C. and R.Sinkovics, R. (2009). The use of partial least squares path modeling in international marketing. Journal of International Marketing, 20, 277-319.

Herold, M. (2007). A multinational perspective to managing End-of-life electronics. Industrial Engineering. Helsinki University.

Hund, S. D. and Morgan, R. M. (1996). The resource-advantage theory of competition: dynamics path dependencies, and evolutionary dimensions. Journal of Marketing, 60(4), 107-114.

Jack, E. P., Powers, T. L., Skinner, L., Jack, E. P., Powers, T. L. and Skinner, L. (2010). Reverse logistics capabilities : antecedents and cost savings. International Journal of Physical Distribution and Logistics Management, 40(3), 228 - 246.

Janse, B., Schuur, P. and Brito, M. P. de. (2009). A reverse logistics diagnostic tool: the case of the consumer electronics industry. The International Journal of Advanced Manufacturing Technology, 47(5-8), 1-19. doi:10.1007/s00170-009-2333-z

Kocabasoglu, C., Prahinski, C. and D.Klassen, R. (2005). Linking Forward and Reverse Supply Chain Investments : The Role of Business Uncertainty (pp. 1-39). Ontario, Canada.

Lawton, C. (2008). The war on returns. Wall Street Journal, D1 (May 20, 1-4.

Lebreton, B. (2007). Strategic Closed-Loop Supply Chain Management. University of Augsburg.

Miele. (2008). Responsibility for Generations - Sustainability report 2008 (pp. 1-48). Retrieved from www.miele-sustainability.com

Mollenkopf, D., Russo, I. and Frankel, R. (2007). The returns management process in supply chain strategy. International Journal of Physical Distribution \& Logistics Management, 37(7), 568-592. doi:10.1108/09600030710776482 
Nunnaly, J. C. and Bernstein, I. H. (1994). Psychometric Theory (3rd ed., pp. 1-125). New York: McGraw-Hill Publications.

Pan Theo, G.-R. (2009). Supply Chain Fit. WHU - Otto Beisheim School of Management.

Pearce, I. J. A. and Robinson, R. (2011). Strategic Management - Formulation, Implementation, and Control. (B. Gordon, Ed.) (12th ed., pp. 1-404). New York: Mc Graw-Hill/Irwin.

Phillip. (2010). Annual Report 2010 (pp. 1-72).

Porter, M. E. (1985). Competitive advantage: Creating and sustaining superior performance. New York: The Free Press.

Quinn, J. B. (1981). Formulating strategy one step at a time. Journal of Business Strategy, 1(3), 42-63.

Rezzan Canan Savaskan, S. B., \& Wassenhove, L. N. V. (2001). Channel Choice and Coordination Issues in a Remanufacturing Environment. Evanston.

Richey, R. G., ChKoen, H., Genchev, S. E. and Daugherty, P. J. (2005). Developing effective reverse logistics programs. Industrial Marketing Management, 34(8), 830-840.

Richey, R. G., Genchev, S. E. and Daugherty, P. J. (2005). The role of resource commitment and innovation in reverse logistics performance. International Journal of Physical Distribution \& Logistics Management, 35(4), 233-257.

Ringle, C., Wende, S. and Alexander, W. (2005). SmartPLS. Hamburg, Germany: SmartPLS. Retrieved from http://www.smartpls.de

Rouse, M. J. and Daellenbach, U. S. (1999). Rethinking research methods for the resource-based view: Isolating sources of sustainable competitive advantage. Strategic Management Journal, 20, 487 494.

S.Hulland, J. (1999). Use of partial least squares (PLS) in strategic management research: A review of four recent studies. Strateg Management Journal, 20(4), 195-204.

Saccani, N., Johansson, P. and Perona, M. (2007). Configuring the after-sales service supply chain: A multiple case study. International Journal of Production Economics, 110(1-2), 52-69.

doi:10.1016/j.ijpe.2007.02.009

Sanchez, R. and Mahoney, J. T. (1996). Modularity, flexibility, and knowledge management in product and organization design. Strategic Management Journal, 17, 63-76.

Shrout, P. E. and Bolger, N. (2002). Mediation in experimental and nonexperimental studies: New procedures and recommendations. Psychological Methods, 7(4), 422-445. doi:10.1037//1082989X.7.4.422

Tenenhaus, M. (2005). PLS path modeling. Computational Statistics \& Data Analysis, 48(1), 159-205.

Tuominen, M., Rajala, A. and Moeller, K. (2004). How does adaptability drive firm innovativeness? Journal of Business Research, 57(5), 495-506.

Verweij, H., Dang, N., Bonney, G. and Janse, B. (2008). Reverse Logistics-How to realise an agile and efficient reverse chain within the Consumer Electronics industry (pp. 1-145).

Wiendahl, H. P. (1999). Components of Adaptability for the planning of competitive factory structures (in German). Deutsche Fachkonferenz Fabrikplanung, 1-12.

Zacharia, Z. G., Sanders, N. R. and Nix, N. W. (2011). The Emerging Role of the Third-Party Logistics Provider (3PL) as an Orchestrator. Journal of Business, 32(1), 40-54.

Zhou, K. Z. and Li, C. B. (2010). How strategic orientations influence the building of dynamic capability in emerging economies. Journal of Business Research, 63(3), 224-231. Elsevier Inc. doi:10.1016/j.jbusres.2009.03.003 